\title{
Conveyor Failure Diagnostics using Sound Visualization Technique
}

\author{
Marek Moravec ${ }^{1 *}$, Miroslav Badida' ${ }^{1}$, Miroslava Jamborova' ${ }^{1}$, Anna Badidova ${ }^{1}$ \\ 1 Technical University of Kosice, Department of Process and Environmental Engineering, Letna 9, 04200 Kosice, \\ Slovak Republic \\ *Corresponding author's e-mail: marek.moravec@tuke.sk
}

\begin{abstract}
Sound visualization methods and techniques are currently applied in various fields to identify and locate individual sources of noise. Conveyor systems are used in various industrial plants. Conveyors require regular inspection and maintenance. In some operations, conveyor systems are difficult to access for the maintenance purposes. During their operation, conveyor systems contribute to increasing the noise levels. The increased noise emitted by a conveyor may signal the failure of a certain part of the system. Such failures can be identified by a sound visualization device and contribute to an effective maintenance of conveyor systems. The paper analyzes specific conveyor systems and identified potential failures of these conveyor systems by using sound visualization methods.
\end{abstract}

Keywords: sound visualization methods, maintenance, failure analysis, conveyor systems.

\section{INTRODUCTION}

In many existing or proposed industrial plants, outdoor belt conveyor transport systems are widely used for transportation different kinds of solid materials. Belt conveyor systems often become an environmental issue for near surroundings due to noise emissions.

Therefore, attention was paid to reducing the noise of these systems and monitoring of reliable operations of conveyor transport systems. Conveyor transport systems are usually part of more complex industrial plants and secure transport of the materials between individual parts. It is important to realize monitoring of the parameters continuously for their reliable and effective operation. Belt conveyor monitoring was described by Wang et al. [11], while design and monitoring for belt conveyor was presented by Lu et al. [12]; other important aspects of online monitoring were described as well $[5,10]$.

During their operation, conveyor transport systems produce noise emissions, but often this noise overlaps with other noise sources in an industrial plant. Due to this reason, individual iden- tification of conveyor transport system is difficult to perform with the classic methods.

Nowadays, new progressive methods for noise identification and localization exist. These methods include sound visualization techniques based on different techniques. The sound visualizations technique includes beamforming, near field acoustic holography, focalization or direct measurement by using special sensors. Noise visualization methods were described in $[6,7]$ and similar issues were dealt with in [8].

Monitoring conveyor transport systems during their operation is important due the several reasons, including: control of correct operations, prediction of maintenance or failure diagnostics. Methodology of failure diagnostics of continuous transport systems was described at Fedorko et al. [2]. Failure of conveyor belt systems is often accompanied with significant increase of noise levels. Due these reason, it is possible to use sound identification and localization techniques for failure diagnostics. After the noise sources identification, it is possible to design a noise reduction measure, select appropriate acoustic material and also consider other relevant properties of the material that were described in $[1,3,9]$. 


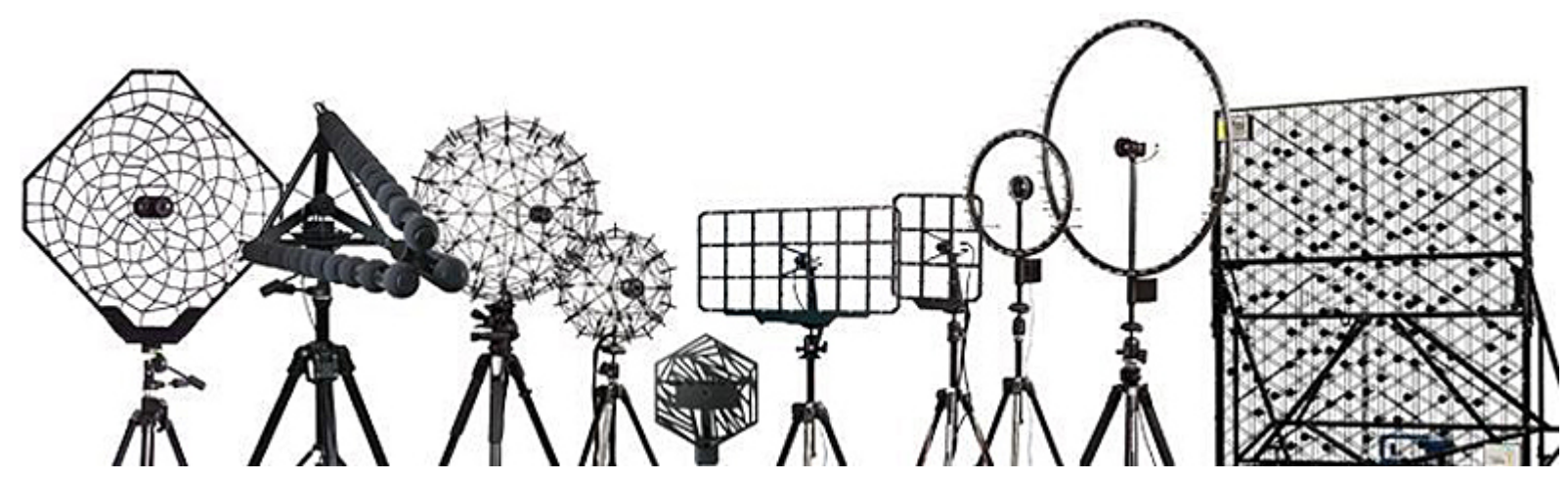

Fig. 1. Microphone arrays [8]

\section{MATERIAL AND METHODS}

Noise visualization techniques provide a new approach for identification and localization of noise sources. The equipment used for noise visualization is generally called acoustic cameras. A digital camera, as part of an acoustic camera, takes an image of the noise emitting object. At the same time an exactly computed microphones array acquires and records the sound waves emitted by the sources of the noise. Specially-developed software calculates a acoustic map and combines the acoustical and the optical images of the noise source. The basic part of acoustic camera is microphone array. Microphone arrays are designed for different measurement distances and different range of frequencies (Fig. 1).

An acoustic camera made by gfai company was used for experimental measurement; it is equipped with a star microphone array that uses beamforming signal processing sound visualization technique featuring following parameters:

- aluminum array structure diameter: $3,4 \mathrm{~m}$,

- number of microphones: 48 ,

- recommended mapping frequencies: $100 \mathrm{~Hz}-$ $13 \mathrm{kHz}$,

- recommended measurement distances: 7-500 m,

- maximum equivalent sound level: $130 \mathrm{~dB}$,

- acoustic maps from $23 \mathrm{~dB}-130 \mathrm{~dB}$,

- operating environment: $0^{\circ} \ldots 45^{\circ} \mathrm{C}$, up to $80 \%$ r.h. Signal processing from microphone array is an important part of the sound visualization. Most commonly used techniques for signal processing are beamforming, nearfield acoustic holography, SONAH or Helmholtz Equation Least Squares (HELS) $[4,8]$.

Beamforming signal processing principle that was used is the far field approach the delay- and-sum beamforming method. This technique is based on special time delays sets for the incoming signals from the microphone array on a spatial location. The correct delay set results in a coherent overlay by adding up all microphone signals. With that special time delay, the area emitting the strongest sound pressure can be found by the creating of acoustic map image (Fig. 2).

\section{RESULTS}

This chapter presents the results of measurement executed by the acoustic camera. The measurement was realized at the stones sorting and crushing line. A belt conveyor is part of this line. The measurement was realized in two different operation modes with load of stones and without load, from the distance of 77 meters, focused on the conveyor belt system. The placement of the acoustic camera and view on the sorting and crushing line with conveyor system is shown in Fig. 3.

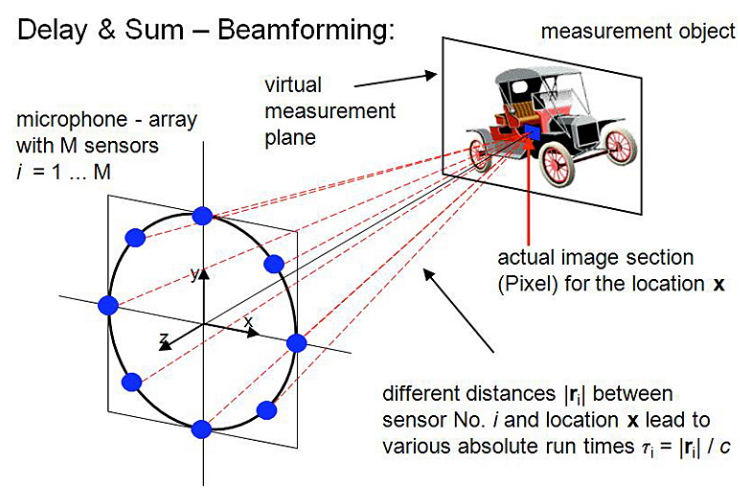

Fig. 2. Delay-sum beamforming and the acoustic camera [6] 


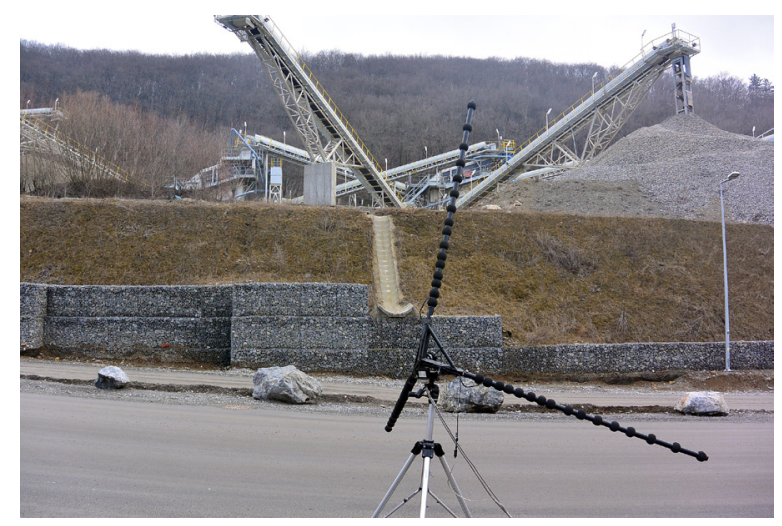

Fig. 3. Installed acoustic camera

Fig. 4 presents the sound visualization of belt conveyor systems during proper operation. This measurement was performed in year 2016 after the installation of new belt conveyor system. The dominant source of the noise can be seen in the input part of belt conveyor. Noise is emitted mainly by the power drive unit and by the stones entering the conveyor. No other relevant sound sources were found.

The control measurement was carried out 20 months later under the same conditions. The measurements were realized in two different operation modes, with load of stones and without load. The measurement was conducted from the distance of 77 meters, focused on the conveyor belt system. The results of the measurement sound visualization acoustic picture are presented in Fig. 5 and 6. Frequency spectrum and spectrogram are presented in Fig. 7 and 8 .

On the basis of the created acoustic images, two sources of noise in both operating modes are clearly visible. The first source was the same as during the first measurement series. This first source was identified as the engine unit and the noise emitted by the stones entering the conveyor. The second source of noise was identified in the upper part of the conveyor. This source of noise was not registered during the first of measurements series. This identified source of the noise in that part means failure of conveyor.

\section{Draft of measurement and valuation procedure}

The draft of measurement procedure for diagnostics of conveyor systems by the sound visualization methods consists of following steps (Fig. 9):

\section{a) Initial analysis}

The first step of the procedure is preliminary inspection of the investigated object and collection of the basic information about the the functions

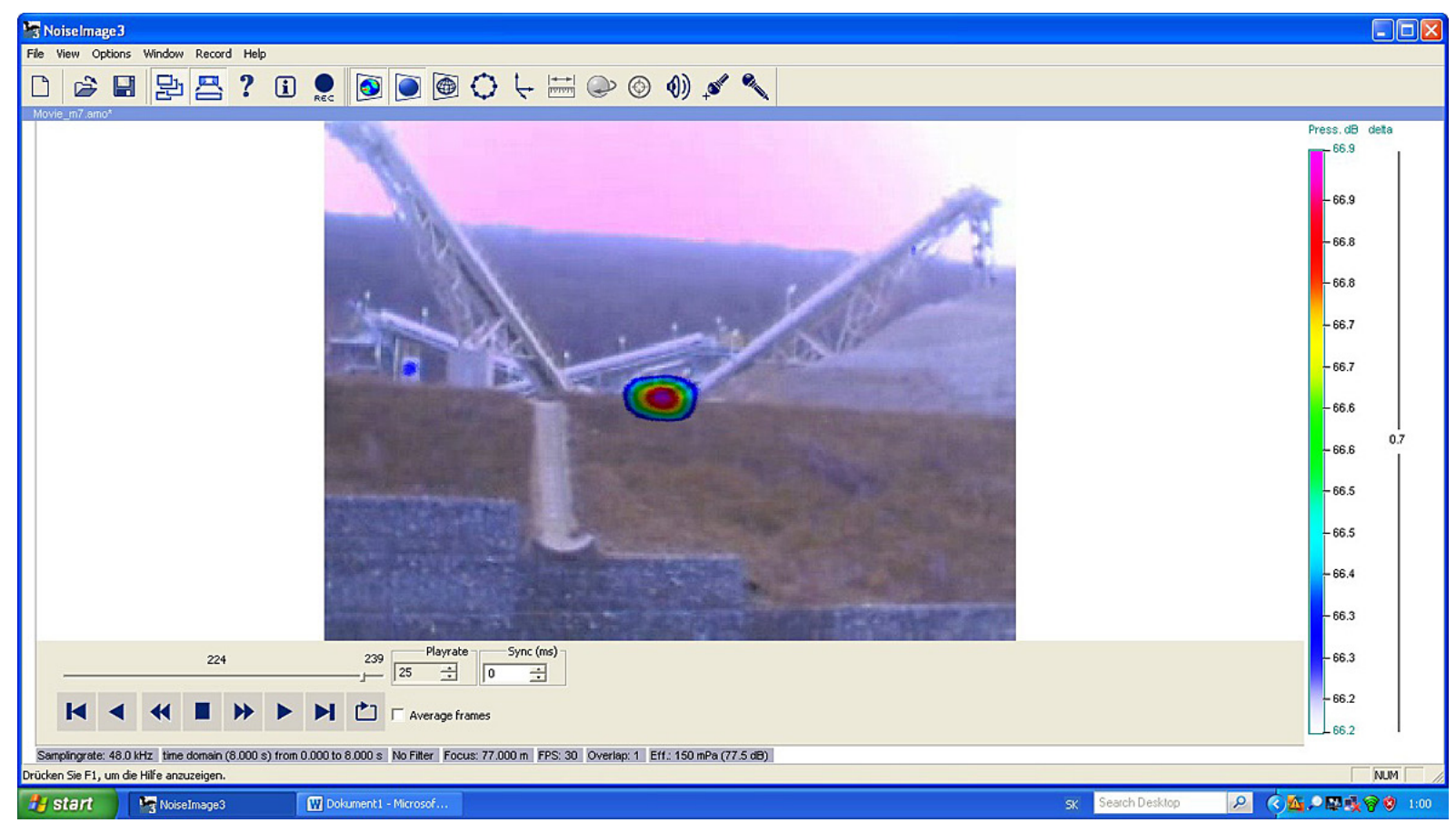

Fig. 4. Sound visualization of belt conveyor with load of stones - correct operation 


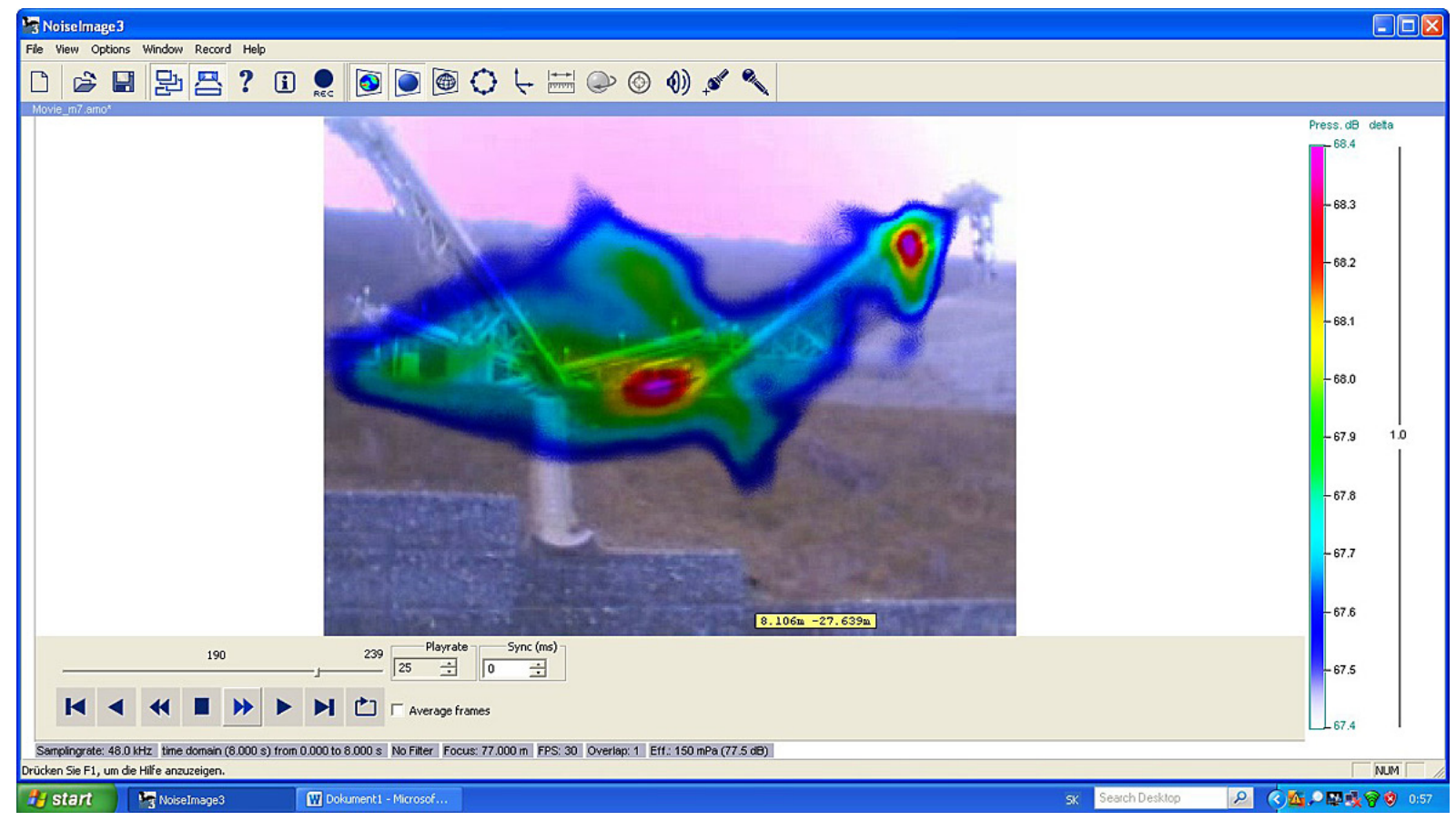

Fig. 5. Sound visualization of belt conveyor with load of stones

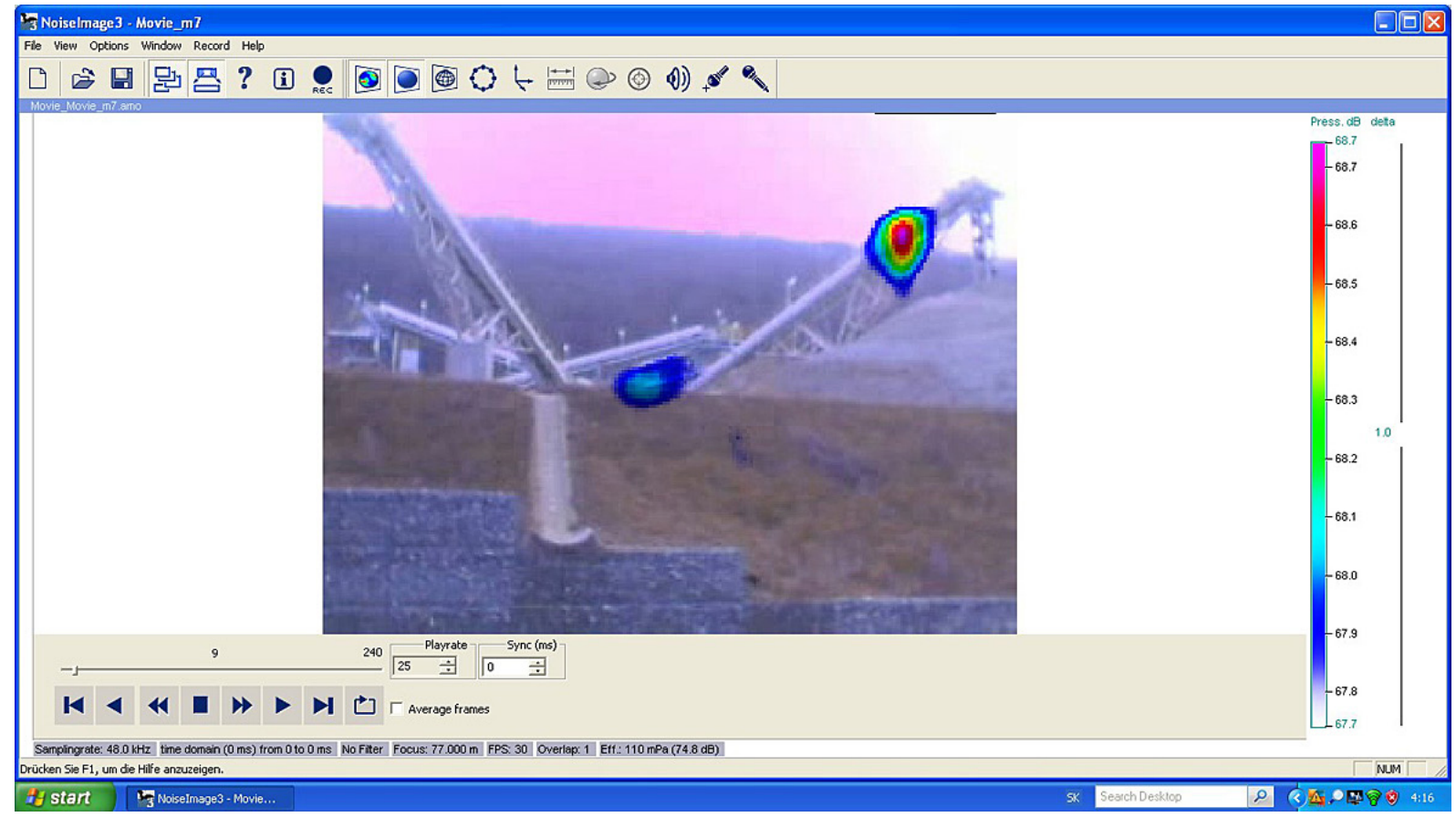

Fig. 6. Sound visualization of belt conveyor without load of stones

and operating modes. Preliminary inspection is executed mostly by the visual and hearing control.

\section{b) Measurement setup}

Before conducting the measurement, it is necessary to take into account the sound parameters of the investigated devices. An important step is to choose the measurement location and the measurement distance towards the measured object. On the basis of sound parameters and the measurement location, an appropriate microphone array is selected. Nowadays, different shapes of microphone arrays are available from various producers. 


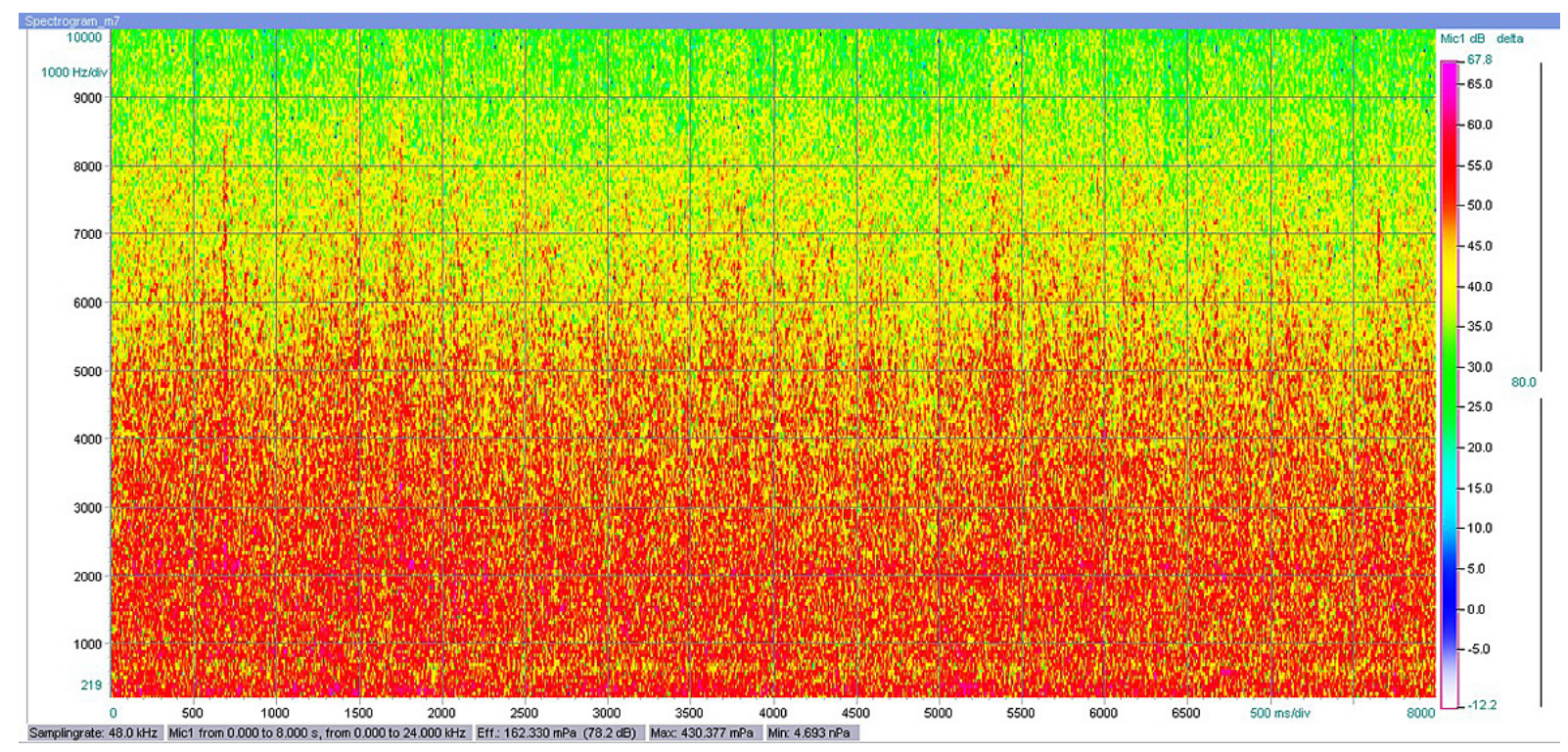

Fig. 7. Frequency spectrum

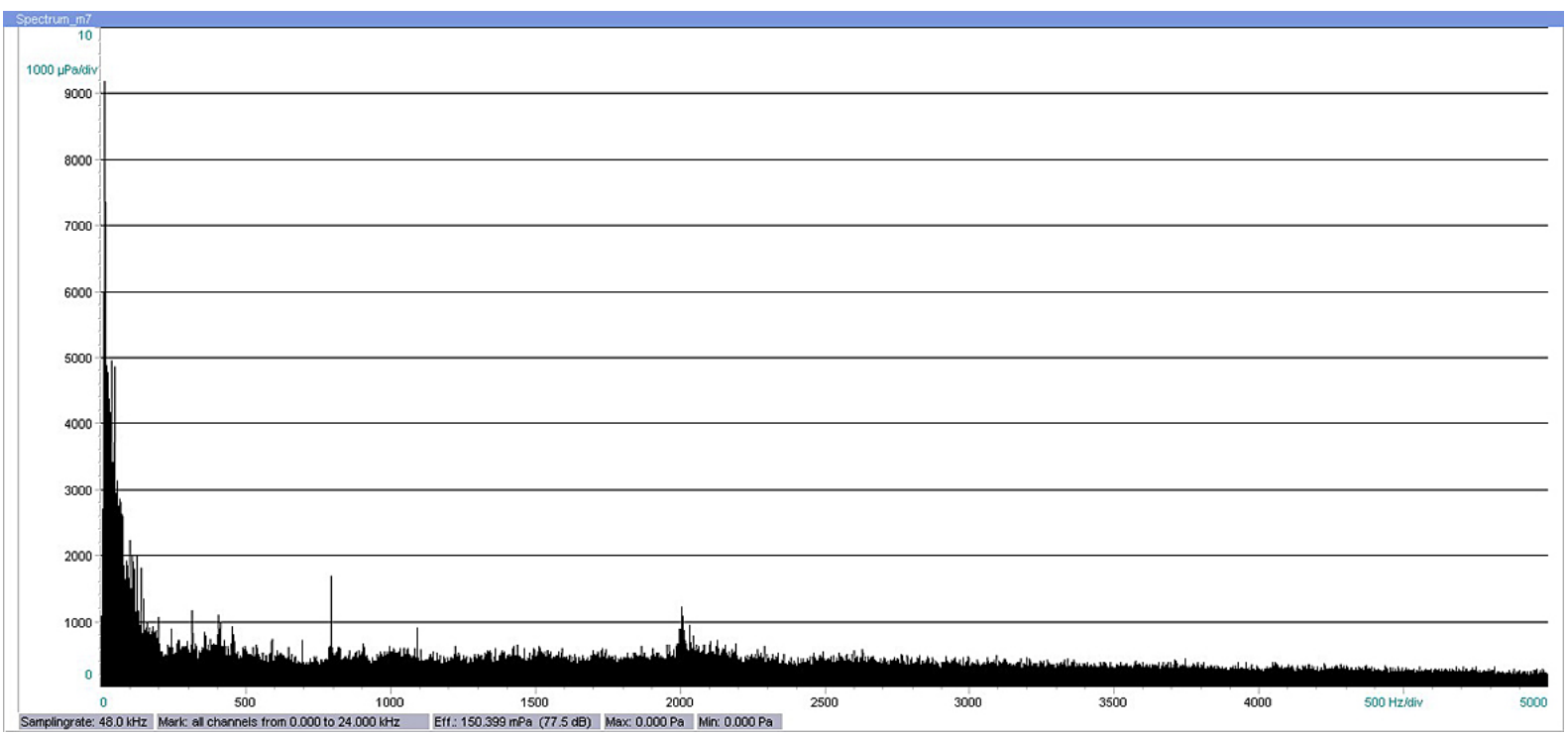

Fig. 8. Spectrogram

\section{c) Measurement realization}

First part of the measurement process is focused on the whole investigated object during different operation modes. On the basis of the preliminary analysis of these measurements, partial dominant noise sources were identified. According to these measurements, the next measurement step is focused on these individual sources of noise.

\section{d) Software processing of acoustic signals}

The measurement is followed by software processing. The results of software processing are:
- Acoustic images for entire spectrum,

- Acoustic movies for entire spectrum,

- Acoustic images and movies for selected frequency range,

- FFT spectrum analysis,

- Octave band analysis,

- Spectrogram analysis,

- Frequency weighting,

- Listening of individual points.

\section{e) Evaluation of individual noise sources}

On the basis of software processing, the analyzed data is obtained. Individual sources of noise 


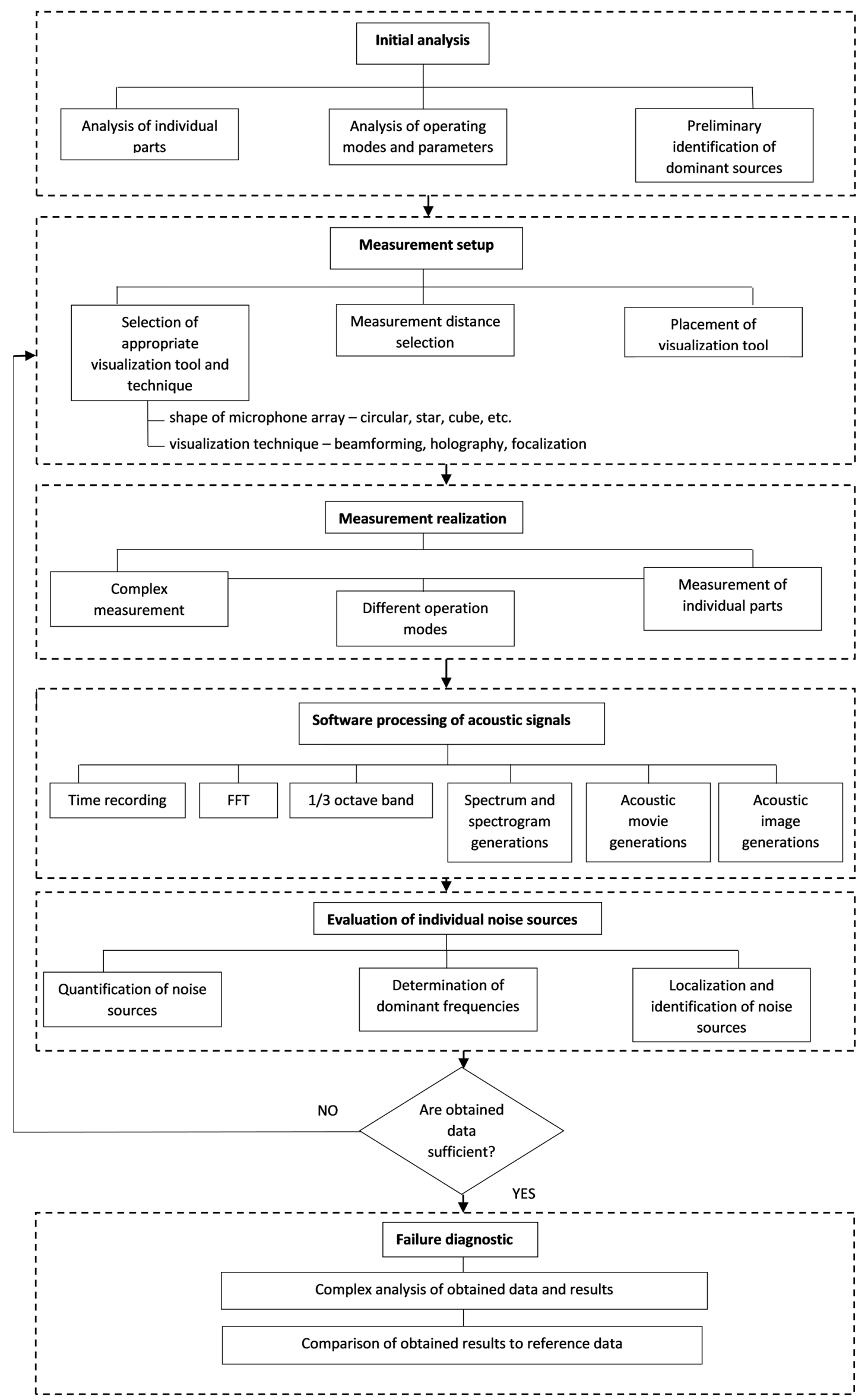

Fig. 9. Measurement and valuation procedure 
are identified, localized and quantified. Frequency spectra are assigned to individual sources of noise.

\section{f) Failure diagnostic}

A complex analysis of the obtained data and results can indicate the failure of individual parts. Increased noise emissions at certain locations may indicate a fault condition. Another suitable method for detecting a failure state is to compare the obtained results with the reference data and searching for the differences in noise emission.

\section{DISCUSSION AND CONCLUSION}

Monitoring of the correct operation of the conveyor at industrial sites is important for efficient company logistics. Several ways of conveyor monitoring are available. One of the possible ways of monitoring conveyor is to use an acoustic camera. The acoustic camera is tool that allows noise visualizations of the noise sources. Increased noise level of conveyor system is often caused by the incorrect operation of conveyor. This noise is emitted by the structural parts of belt conveyor, frame, belt, idler rolls and drums. These parts of belt conveyor are hardly accessible and their monitoring and diagnostic is due this reason very difficult. The measurement performed by means of an acoustic camera allows fast measurement and diagnostics from a larger distance. The results of the measurement are generated as a colored map acoustic images that clearly show the location and identification of sound sources. According to the proposed measurement and valuation procedure, a failure diagnostic of the belt conveyor can be performed.

\section{Acknowledgments}

This paper was written in frame of the work on the projects KEGA 041TUKE-4/2018 (50\%). The Slovak Research and Development Agency supported this work under the contract No. APVV- 0432-12 (50\%).

\section{REFERENCES}

1. Debski H., Teter A., Kubiak T., Samborski S. Local buckling, post-buckling and collapse of thinwalled channel section composite columns sub- jected to quasi-static compression. Compos Struct., 136, 2016, 593-601.

2. Fedorko G., Liptai P., Molnár V. Proposal of the methodology for noise sources identification and analysis of continuous transport systems using an acoustic camera. Eng Fail Anal., 83, 2018, p. 30-46.

3. Sabadka D.; Molnar V.; Fedorko G. et al. Optimization Of Production Processes Using The Yamazumi Method. Adv Sci Technol Res J, 11 (4) 2017, 175-182; DOI: 10.12913/22998624/80921.

4. Hunady R., Hagara M. A new procedure of modal parameter estimation for high-speed digital image correlation. Mech Syst Signal Process., 93, 2017, pp. 66-79.

5. Molnár V., Fedorko G., Andrejiová M., Grinčová A., Michalik P. Online moniroring of a pipe conveyor. Part I: Measurement and analysis of selected operational parameters, Meas. J. Int. Meas. Confed. 94, (2016), 364-371.

6. Moravec M., Liptai P. Innovative methods and equipment for noise visualization. 2017. In: ICEEE 2017. - Košice. elfa s.r.o., 2017 pp. 130-133.

7. Moravec M., Liptai P. Methods and progressive equipment for sound visualization of noise sources. In: Scientific Letters of Academic Society of Michal Baludansky. 2017. pp. 131-134.

8. Moravec M., Liptai P., Badida M., Dzuro T. Dynamic noise visualization methods for identification of noise sources. SGEM 2014. 14th international multidiscilinary scientific geoconference - GeoConference on Ecology, Economics, Education and Legislation conference proceedings. Volume 1. 17-26, June, 2014, Albena, Bulgaria. - Sofia: STEF92 Technology, 2014 pp. 207-212. ISBN 978-619-7105-17-9 - ISSN 1314-2704.

9. Pavlík M., Kruželák L., Mikita M., Špes M., Bucko S., Lisoň L., Kosterec M., Beňa L., Liptai, P. The impact of electromagnetic radiation on the degradation of magnetic ferrofluids. Arch Electr Eng., 66(2), 2017. pp. 361-369.

10. G. Lodowijks, J. Ottjes. Inteligent belt conveyor monitoring a control. Theory and application. Int. Mater. Handl. Conf. BeltCon, Randburg, South Africa, 2007, pp-1-9.

11. Shasha Wang, Weina GuoWu, WenRuihan, ChenTing, LiFang Fang. Research on Belt Conveyor Monitoring and Control System. International Conference on Information Computing and Applications.ICICA 2010: Information Computing and Applications pp. 334-339.

12. Qing Lu, Xiaohui Wang, Liyun Zhuang. Research and Design of Monitoring System for Belt Conveyor. In: 2012 International Conference on Computer Science and Service System. IEEE,2012. pp. 1943-1945. 